\title{
Mechanical behavior of wood-plastic composites investigated by 3D digital image correlation
}

\author{
Talel Ben Mbarek', Laurent Robert ${ }^{2}$, Francoise Hugot ${ }^{3}$ and \\ Jean-José Orteu ${ }^{2}$
}

\begin{abstract}
The tensile behavior of wood-plastic composite (WPC) with or without additive is studied using full-field strain measurements by 3D digital image correlation. It is shown that macroscopic values of the longitudinal strain are close to those measured by mechanical extensometer using standard mechanical tests. The modulus of elasticity provided by a Maxwell-Bingham model fitted to the experimental tensile curves is analyzed for several WPC formulations depending on the wood contents and the presence of additive. Color maps of the spatial strain distribution are commented. Moreover, the damage behavior and the degree of heterogeneity are analyzed thanks to the spatial standard deviation of the longitudinal strain field.
\end{abstract}

\section{Keywords}

composite material, digital image correlation, stereo-correlation, wood plastic composite, mechanical properties, elastic properties, strain measurement, strain heterogeneity

\section{Introduction}

Nowadays, wood-plastic composites (WPC) are used in several sectors, such as garden furniture, automotive, and buildings (infrastructure and finishing). WPC are predicted to have $25 \%$ of the market in $2009 .{ }^{1}$ WPC are composed of thermoplastic polymers, often recycled, and of wood fibers in different sizes and proportions. ${ }^{2} 4$ This kind of material benefits from the relatively low density of wood, low cost, good mechanical properties, as well as its recyclability. Thermoplastic fraction reduces the fragility while improving the resistance against biological attacks. The thermoplastic polymer matrix show many qualities (e.g., low density, low cost) and are widely available in the market. They can be polyethylene, polypropylene, polyvinyl chloride, and polystyrene. The characteristics of wood in the composite will play a role in the adequate choice of plastic, as well as the chemical surface treatments on the interfacial adhesion between fibers and polymer. ${ }^{5}$

Many experimental methods have been used to study the mechanical behavior at macro/micro level, the properties of wood/plastic interface, and the surface properties of WPCs. For instance, scanning electron microscopy (SEM) is used for characterizing the morphology of the composite surface in order to compare injection molded and extruded composites. ${ }^{6}$ Attenuated total reflection Fourier transform infrared (ATR-FT-IR) spectroscopy is also used to identify functional groups present at the surface of WPC. Cui et al. ${ }^{7}$ also used FT-IR to evaluate the surface chemistry of the treated fibers. The authors found that the treatment by the alkaline followed by silane together with the maleated polypropylene (MAPP) coupling agent increased the mechanical performances of the wood/ recycled plastic composite (WRPC) material. The content of wood fiber affects the flexural strength, the flexural modulus, and impacts strength of these WRPC

'LETTM, Ecole Supérieure des Sciences et de Technologie de H-Sousse, rue Lamine ElAbbassi, 40 I I H-Sousse, Tunisie.

${ }^{2}$ Université de Toulouse, Mines Albi, Institut Clément Ader (ICA), Campus Jarlard, 8I0I3 Albi, France.

${ }^{3}$ Université de Limoges, ENSIL, 16 rue Atlantis, Parc ESTER Technopole, BP 6804, 87068 Limoges, France.

\section{Corresponding author:}

Francoise Hugot, Université de Limoges, ENSIL, 16 rue Atlantis, Parc ESTER Technopole, BP 6804, 87068 Limoges, France

Email: hugot@ensil.unilim.fr 
materials. It is generally highlighted in the literature that macroscopic properties are mainly related to the association, nature, proportion, and orientation of the components. ${ }^{8} 10$ Adhikary et al. ${ }^{11}$ investigated the stability, the mechanical properties, and the microstructure of WPC which were made using either recycled or virgin high-density polyethylene (HDPE) with wood flour (Pinus radiata) as filler. Using standard mechanical tests, they found that bending and tensile properties of the composite based on recycled HDPE were equivalent to those based on virgin HDPE. Adding MAPP by $3-5 \mathrm{wt} \%$ significantly improved both the stability and the mechanical properties by increasing the interfacial bonding, which is confirmed by SEM analysis. This is observed also in ${ }^{12}$ where the authors showed that added coupling agent increases the bending properties because the modulus of elasticity (MOE) becomes higher than that of the specimen made without any chemicals. Najafi et al. ${ }^{13}$ studied the mechanical properties from sawdust and recycled plastics and found from tensile and flexural tests that the mechanical properties of WRPC containing recycled HDPE and PP were statistically similar to those of composites made from virgin plastics. Hugot and Cazaurang ${ }^{14}$ performed mechanical (tensile) tests and SEM analysis to study the mechanical behavior of wood pine composite fiber/HDPE. They found that the MOE increases with wood content for specimen manufactured both by extrusion and injection processes. Michaud and Hugot ${ }^{15}$ studied the mechanical behavior of WPC product for decking application using tensile, compressive, and bending tests and confirmed the anisotropy of extruded WPC.

Although many studies are devoted to evaluating and understanding WPC mechanical behavior from tensile and bending tests using cross-head displacement or mechanical extensometers, few studies used non-contact optical methods to analyze the mechanical performance of WPCs. Srentovic et al. ${ }^{16}$ studied the mechanism of stress transfer in a single wood fiber-LDPE composite specimen during tensile test by means of Electronic Speckle Pattern Interferometry (ESPI). They compared the strain distribution measured by ESPI and calculated by finite element method and analytical analyses, and demonstrated that ESPI is a valuable tool for the direct measurement of local strain around a single wood fiber in composite materials. Godara et al. ${ }^{17}$ investigated the influence of additives on the global mechanical performances and the microscopic strain localization in PPbased WPC by digital image correlation (DIC) coupled with tensile tests. Giving access to the full surface strain field of the specimen, the DIC technique allows a detailed investigation of complex micromechanical questions associated with the distribution of the strain in these heterogeneous materials. Thanks to that, they resolved the influence of the amount of coupling agent, biopolymers, and inorganic fillers on the structural integrity of the WPC material. At the mesoscale (field of view of $3 \times 10 \mathrm{~mm}^{2}$ for $316 \times 1050$ pixels), they observed both high- and low-strain domains along the longitudinal axis of the specimen related to the influences of amount of PP and adding other constituents, that is studied by a sectional analysis.

The work presented in this article proposes the analysis of the mechanical behavior of a HDPE-based injected wood fibers WPC using 3D digital image correlation (3D-DIC) also known as stereo-correlation. ${ }^{18}$ Some formulation specimens have been added with a maleic anhydride grafted polyethylene (MAPE) coupling agent to improve the interfacial adhesion between wood fibers and plastic. First, the 3D-DIC results have been compared to classical extensometer results for validate the method. In order to determine the macroscopic mechanical properties of the WPC, the MOE is evaluated by a Maxwell-Bingham model adjusted on the experimental strain-stress curves and the module of rupture (MOR) is measured. Next, the degree of heterogeneity relating to the damage level of different WPC formulations (percentages of wood fibers) is investigated by mean of spatial standard deviation (SD) of the longitudinal strain field during tensile tests. These results will make it possible to better understand the behavior during the damage of these composites.

\section{Material}

HDPE granulates are Lacqtene from ATOFINA. Softwood Pinus pinaster sawdust is screened (mesh size $2 \mathrm{~mm}$ ) with the morphological characteristics described in Table 1. Optical scanning device of fiber (MorFi LB01 system from Techpap) is used to determine the size distribution in frequency of the wood raw material (Table 1). The very small elements (length $<30 \mu \mathrm{m}$ ), called fines, represent about $76 \%$ in total length and $17 \%$ of the total surface of all elements analyzed.

After wood fiber drying, premixed wood/HDPE pellets are done by extrusion process in a single screw device. Then, $4 \times 10 \mathrm{~mm}^{2}$ section tensile specimens are produced by injection process. Parameters are set at: injection temperature $200^{\circ} \mathrm{C}$, zone $1 \quad 160^{\circ} \mathrm{C}$, zone $2170^{\circ} \mathrm{C}$, zone $3180^{\circ} \mathrm{C}$, mold temperature from $50^{\circ} \mathrm{C}$ to $70^{\circ} \mathrm{C}$; injection pressure 100 , injection speed 47, speed of screw $60 \mathrm{tr} / \mathrm{min}$; holding time$6 \mathrm{~s}$, cooling time $25 \mathrm{~s}$.

Indexation of realized formulations of WPC with or without additive is presented in Table 2. Additive used as compatibilizer is MAPE, OREVAC 18307 product from Arkema with a melt index of $2.5 \mathrm{~g} / 10 \mathrm{mg}$. Two formulations are studied: $10 \%$ wood content and $30 \%$ wood content. Depending on wood content, adjustments of injection parameters had to be done to obtain acceptable 
Table I. Morphological characteristics and size distribution of wood fiber (P. pinaster)

\begin{tabular}{|c|c|c|}
\hline Fibers & Size & Frequency (\%) \\
\hline $\begin{array}{l}\text { Average length } \\
\text { (without thin fibers) }\end{array}$ & $220 \mu \mathrm{m}$ & \\
\hline $\begin{array}{l}\text { Average thickness } \\
\text { (without fines) }\end{array}$ & $30 \mu \mathrm{m}$ & \\
\hline Curvature (without thin fibers) & $4.5 \%$ & \\
\hline \multirow[t]{8}{*}{ Size distribution (in length \%) } & Fines $<30 \mu \mathrm{m}$ & 76 \\
\hline & $30 \quad 150 \mu \mathrm{m}$ & 9.7 \\
\hline & $150250 \mu \mathrm{m}$ & 6.5 \\
\hline & $250300 \mu \mathrm{m}$ & 1.5 \\
\hline & $300450 \mu \mathrm{m}$ & 2.5 \\
\hline & $450680 \mu \mathrm{m}$ & 1.3 \\
\hline & $6801030 \mu \mathrm{m}$ & 1.2 \\
\hline & $>1550 \mu \mathrm{m}$ & 1.3 \\
\hline
\end{tabular}

Table 2. WPC formulations

\begin{tabular}{ll}
\hline Index & Description \\
\hline iWPCfI0 & $10 \%$ wood without additive \\
IWPCf30 & $30 \%$ wood without additive \\
iaWPCfI0 & $10 \%$ wood with $3 \%$ of MAPE additive \\
iaWPCf30 & $30 \%$ wood with $3 \%$ of MAPE additive \\
\hline
\end{tabular}

specimens. It will be shown in the following that the performance of the WPC formulation can be influenced by the content of wood fibers and the addition of the coupling agent.

\section{Method}

\section{Tensile test}

Tensile tests are based on the standard guide for evaluating mechanical properties of WPC products (ASTM D 7031-04). They are performed at room temperature on an electro-mechanical universal testing machine (Instron $5800 \mathrm{R}$ ) with a cross-head speed of $2 \mathrm{~mm} / \mathrm{min}$. A set of three specimens for each formulation is tested. The dimensions of the specimens are $10 \mathrm{~mm}$ in width, $4 \mathrm{~mm}$ in thickness, and $150 \mathrm{~mm}$ in length. Strain measurements can be performed using a mechanical extensometer that is characterized by $50 \mathrm{~mm}$ gage length, or by $3 \mathrm{D}-\mathrm{DIC}$ (see next section).

It is known that due to the global non-linear behavior of WPC, mechanical properties such as MOE are difficult to obtain. Indeed standard guide recommendations are often not suitable for this kind of composite. It has been shown in the work of Hugot and Cazaurang ${ }^{14}$ that there are large differences between the MOE evaluated using specification for reinforced plastic standard (MOE taken between $5 \times 10^{-4}$ and $2.5 \times 10^{-3}$ of strain) and the one, defined as tangent MOE, based on the first derivate of a stress/strain fitting function. The authors conclude that the tangent MOE is the more appropriate to calculate tensile elastic modulus and confirm an underestimation of MOE standard method due to the non-linear behavior. In this study, the non-linear strain/stress relationship is modeled, in the area where the stress remains monotonous, by the Maxwell-Bingham equation:

$$
\sigma \quad a(1-\exp (-b \varepsilon))
$$

where $a$ and $b$ are parameters. A fitting is done by minimization in the least-squares sense of the difference between the experimental curve and the MaxwellBingham equation, resulting to an optimized set of parameters $a$ and $b$. The MOE is then calculated as the first derivate at $\varepsilon \quad 0$ of the fitted Maxwell-Bingham:

$$
\left.\frac{\partial \sigma}{\partial \varepsilon}\right|_{\varepsilon \quad 0} a b
$$

\section{Three-dimensional DIC}

The DIC method has been successfully employed for characterizing the heterogeneity of a lot of materials: metallic materials considering heterogeneity at the macroscale, as plastic strain localization and necking ${ }^{19}$ or at the microscale, ${ }^{20} 23$ short-glass-fiber reinforced epoxy composites, ${ }^{24}$ polymeric foams. ${ }^{25}$ This technique has been also used, for example, for analyzing the mechanical behavior and the local anisotropy of crimped glass wool, ${ }^{26}$ and for the characterization of the thermohydromechanical behavior of rock-clay matrix. ${ }^{27}$ In this study, the degree of heterogeneity related to the damage level of different WPC formulations is investigated, thanks to the 3D-DIC technique during tensile tests.

The 3D-DIC method is based on both DIC and computer stereo vision (utilization of two cameras), and was developed at the end of the past century. ${ }^{28}$ This technique uses a DIC algorithm to determine point correspondences between two images of a specimen acquired from two different view points by two rigidly bounded cameras. The correlation scores are computed by measuring the similarity of a fixed subset window in the first image to a shifting subset window in the second one. A first-order 2D shape function in the subset and a zero normalized sum of square difference correlation criterion are used. Sub-pixel correlation is performed using B-spline gray level interpolation. After determining the calibration parameters for each camera as well as the 3D relative position/orientation of the two cameras (pinhole model and radial distortion of third-order), the 
3D shape of the specimen can be reconstructed by triangulation from the image-points correspondences founded by DIC. To determine the $3 \mathrm{D}$ displacement field, DIC is also used to determine image-points correspondences between the stereo pairs acquired before and after deformation. The surface strain field is obtained as follows: at each matched point, a displacement function, assumed as affine, is fitted using a set of $N \times N$ neighboring matched points chosen in a square surface. The Green-Lagrange $2 \mathrm{D}$ strain tensor is then computed using the estimated terms of the displacement function. Computations are done in a local coordinate system (aligned with a local tangent plane to the undeformed surface) obtained by a leastsquare plane fitting of this square surface. A complete description of the 3D-DIC technique can be found in the literature. ${ }^{18}$

The stereo rig is composed of two 8 bit Qicam (Qimaging) CCD cameras allowing a $1360 \times 1036$ pixels resolution. They are equipped with Nikon $50 \mathrm{~mm}$ aperture 11 lenses. Two synchronized images are taken at the frequency of $2 \mathrm{~Hz}$. The calibration and numerical image processing are carried out with the assistance of the Vic$3 \mathrm{D}^{\circledR}$ commercial software. ${ }^{29}$ For this study, because of the very small optical contrast of the fibers in the matrix, and in order to increase the spatial resolution and the accuracy of the strain measurement, a randomly distributed white paint pattern is applied on the painted-inblack side of the specimens. The suitability of a speckle pattern (pattern density) for accurate displacement and strain measurements with DIC is an important issue that has been investigated by several authors and that is still under study. In Sutton et al., ${ }^{18}$ for instance, the issue of optimal sampling of the features in each speckle pattern (to avoid aliasing) is addressed and some rules of thumb for determining the appropriate patterning and the optimal speckle/subset size for accurate measurements are provided. Dimensions of the region of interest (ROI) are $60 \times 10 \mathrm{~mm}^{2}$, with a magnification factor $g 16.5 \mathrm{px} /$ $\mathrm{mm}$. In these conditions, chosen 3D-DIC parameters are: a $f \times f$ subset size with $f \quad 19$ pixels corresponding to a displacement spatial resolution of $f / g \quad 1.15 \mathrm{~mm}$. Figure 1 defines the ROI, the subset size, and the speckle pattern. The strain spatial resolution (optical strain gage size) can be considered to be the size of the square surface of the $N \times N$ neighboring matched points. As the grid step size, $p$, of the matched points is chosen equal to 5 pixels and $N \quad 5$ (smaller value allowed by the software), the strain gage size (optical gage size) is equal to $p(N-1) / g \quad 1.2 \mathrm{~mm}$ (20 pixels). This value is the minimum value for the strain spatial resolution and has been chosen because local strain gradients are expected during deformation. It has been shown in another study ${ }^{30}$ that strain standard uncertainty can be estimated to $10^{-4}$ in similar experimental conditions.

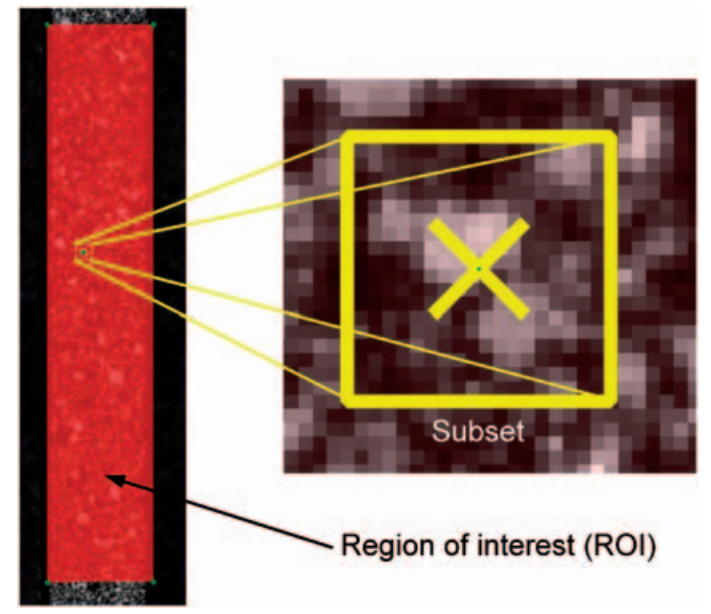

Figure I. ROI, subset, and speckle pattern.

It should be noted that 3D-DIC was used in this study instead of standard (2D) DIC mainly because in 2DDIC the specimen must be planar, positioned parallel to the camera sensor, and must undergo a planar deformation without any out-of-plane displacement. In practice, this is difficult to guarantee, and an apparent strain could be added to the real strain undergone by the specimen. ${ }^{31}$ 3D-DIC does not rely on any hypothesis as the full 3D displacement can be measured. Shapes of the injected specimens and out-of-plane displacements were measured in order to verify these assumptions. As expected, surface of the specimens emphasized a relatively important $\mathrm{V}$-shape due to the injection process, with a mean size of the groove of $0.2 \mathrm{~mm}$, as it can be seen in Figure 2(a). This will generate strain measurement errors if 2D-DIC is used. An out-of-plane displacement $\Delta Z$ of about $0.3 \mathrm{~mm}$ at each edges $(+0.36 \mathrm{~mm}$ for the top and $-0.22 \mathrm{~mm}$ for the bottom) can be also measured during the experiments, as presented in Figure 2(b) for an iWPCf10 specimen undergoing about $7.4 \%$ longitudinal strain. The out-of-plane strain errors if 2D-DIC had been used can be estimated ${ }^{31}$ as $\Delta \varepsilon_{y y} \quad \Delta \varepsilon_{x x} \quad \Delta Z / Z$ where $Z \approx 500 \mathrm{~mm}$ is the distance from the specimen to the camera. Out-of-plane strain errors value will be in this configuration of more than $0.06 \%$ at each edges.

\section{Results and discussion \\ Validation of the 3D-DIC measurements}

In this section, the Green-Lagrange longitudinal strain measured by 3D-DIC is compared to the one measured by the mechanical extensometer during the same tensile test. For that, the magnification is adjusted so that the length of the considered ROI will be the same of the gage length of the extensometer, $L_{0} 50 \mathrm{~mm}$. Measured 
(a) $2[\mathrm{~mm}]$

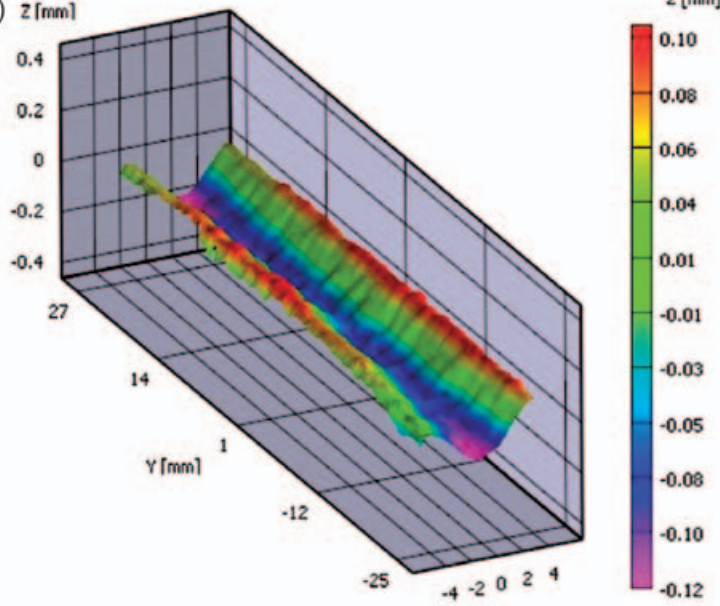

(b)

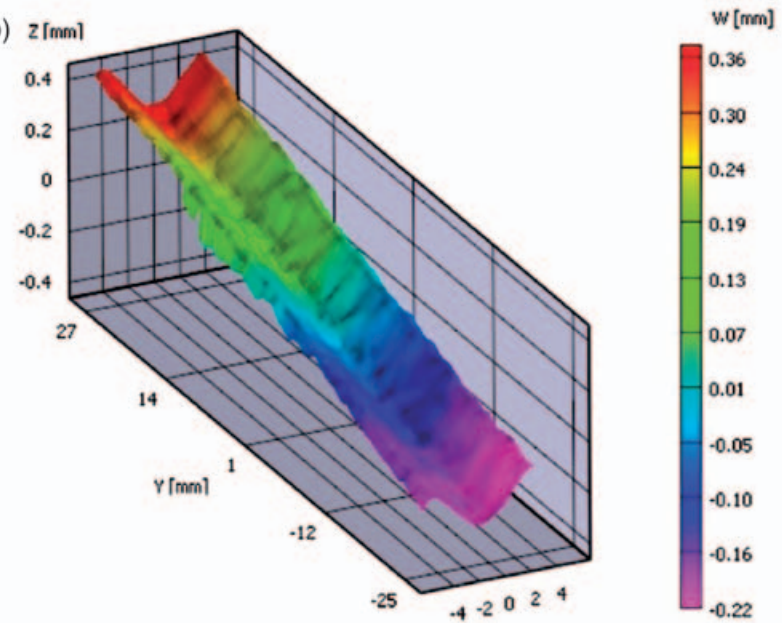

Figure 2. (a) Shape of the surface of the injected specimen before deformation. (b) Out-of-plane displacement field for $7.4 \%$ longitudinal strain (iWPCfIO specimen). Both shapes are represented in the same basis.
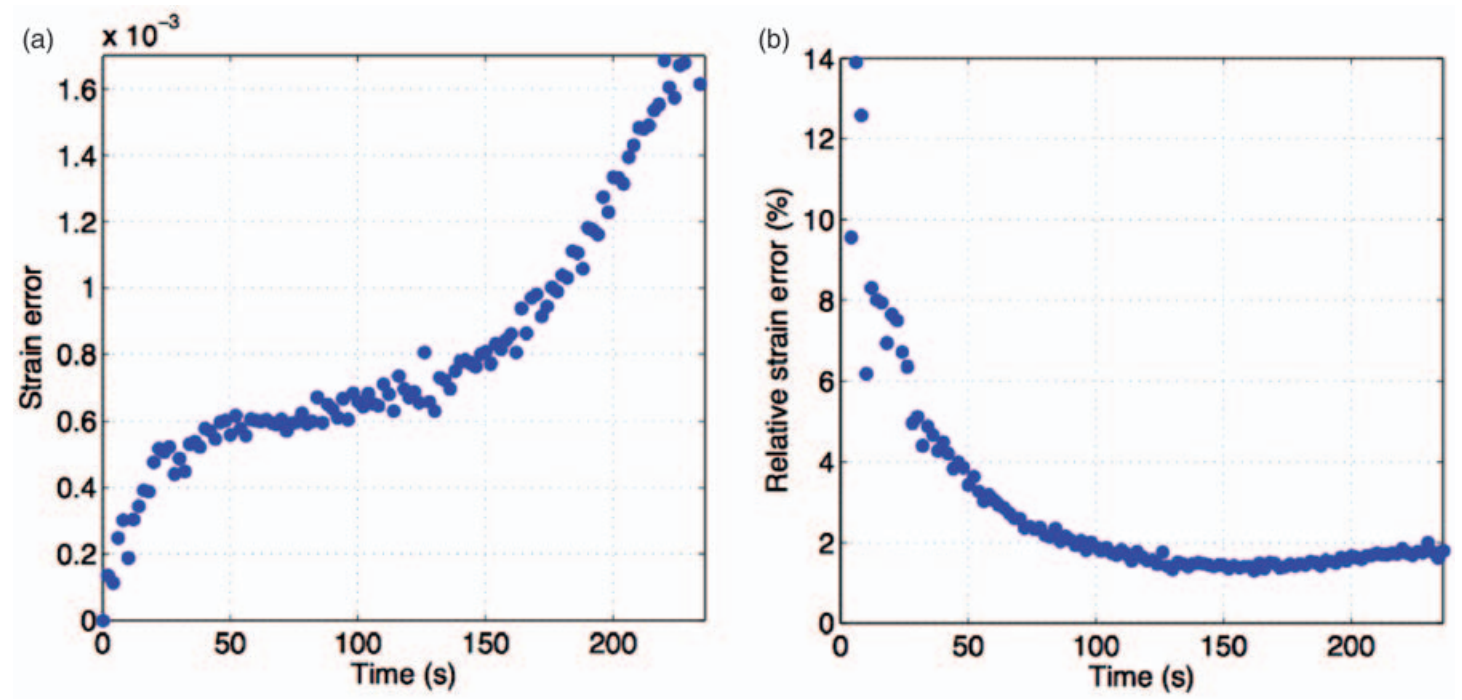

Figure 3. Errors between strain measured by $3 \mathrm{D}-\mathrm{DIC}$ and by mechanical extensometer function of time during the tensile test of an iaWPCf30 sample: (a) strain error $\varepsilon_{y y}^{\mathrm{DIC}} \quad \varepsilon_{y y}^{\mathrm{ME}}$ and (b) relative error $100^{*}\left(\begin{array}{ll}\varepsilon_{y y}^{\mathrm{DIC}} & \varepsilon_{y y}^{\mathrm{ME}}\end{array}\right) / \varepsilon_{y y}^{\mathrm{ME}}$.

values from the mechanical extensometer are computed as Green-Lagrange strain by $\varepsilon_{y y}^{\mathrm{ME}}\left(\Delta L / L_{0}\right)+$ $\frac{1}{2}\left(\Delta L / L_{0}\right)^{2}$ where $\Delta L$ is the variation of length. The strain measured by $3 \mathrm{D}$-DIC is computed as the mean spatial strain over all the $N$ calculated points $\varepsilon_{y y}^{\mathrm{DIC}} \frac{1}{N} \sum_{i 1}^{N}\left(\varepsilon_{y y}\right)_{i}$ in the ROI. Note that with our video acquisition device (Vic-snap ${ }^{29}$ ), the time is manually synchronized with the extensometer acquisition device, with a time delay less than $1 \mathrm{~s}$, that needs to be updated. As the camera frame rate $(0.5 \mathrm{fps})$ and the frequency acquisition of the extensometer $(5 \mathrm{~Hz})$ are not the same, the extensometer strain vs. time curve which having the largest resolution is interpolated by a fifthorder polynomial approximation to obtained the value of $\varepsilon_{y y}^{\mathrm{ME}}$ at each image time corresponding to $\varepsilon_{y y}^{\mathrm{DIC}}$. Figure 3 (a) presents the strain error $\left(\varepsilon_{y y}^{\mathrm{DIC}}-\varepsilon_{y y}^{\mathrm{ME}}\right)$ and Figure 3(b) the relative error $100 *\left(\varepsilon_{y y}^{\mathrm{DIC}}-\varepsilon_{y y}^{\mathrm{ME}}\right) / \varepsilon_{y y}^{\mathrm{ME}}$ in percent function of time during the tensile test of an iaWPCf30 sample. Figure 3(a) shows that the error is maximum at the end of the test ( $t \quad 236 \mathrm{~s})$ and reaches $1.7 \times 10^{-3}$ for a global longitudinal strain of about $10 \%$. This corresponds to a relative error of 0.019 (less than $2 \%$ ) as it can be seen in Figure 3(b). Moreover, Figure 3(b) shows that the relative error is maximum for small strain and 


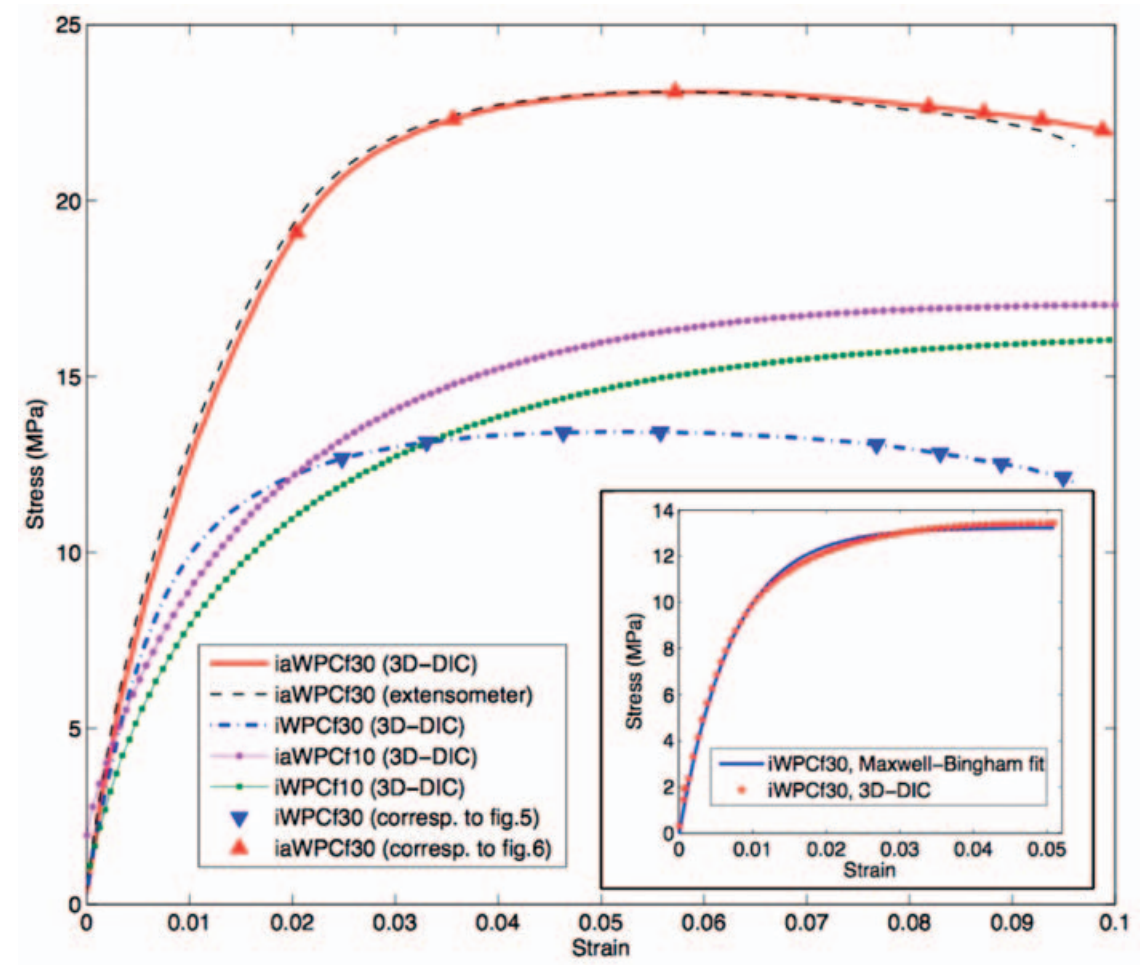

Figure 4. Stress/strain curves of the four studied WPCs with varying the wood percentage and with or without MAPE additive.

reaches $14 \%$ because of the resolution of the 3D-DIC measurement and because of the unsynchronized time. However, errors are globally small according to the amplitude of strain encountered during the tensile tests of WPC. Note that these small differences on the strain measurements are propagated when the MOE is evaluated from the stress/strain curve, and a small difference of about $4 \%$ in the evaluated MOE is found $(1881 \mathrm{MPa}$ for the extensometer method compared to $1974 \mathrm{MPa}$ for the 3D-DIC method), as it can be seen in the next section. These results confirm that strain values measured by $3 \mathrm{D}$-DIC are in agreement with strain values measured by mechanical extensometers. Moreover, extensometer values remain highly dependent on their location on the sample because of strain localization phenomena. As the 3D-DIC method can determine a strain mean value by averaging all the strain values of the field being considered, the material heterogeneity becomes less influential. Full-field measurements could give obviously complementary information, particularly when considering damage.

\section{Mechanical properties of iWPCf and iaWPCf}

The 3D-DIC method is used during tensile tests, at room temperature, of the four WPC formulations specimens (with or without additive and with $10 \%$ or $30 \%$ wood;
Table 2). The value of the longitudinal strain is evaluated as the mean spatial strain over all the $N$ calculated points in the ROI using parameters of the 3D-DIC method presented below. The stress is the global force divided by the initial section. Figure 4 presents all the results. As an illustration, for the iaWPCf30 formulation, both the strain measured by 3D-DIC and by extensometer are presented and are clearly close to be superimposed (dashed line and large solid line in Figure 4). The tensile curves show a global non-linear behavior. As it is explained below, this behavior can be modeled by the Maxwell-Bingham model (Equation (1)). A fitting of this model is presented in an insert in Figure 4 for the iWPCf30 formulation (blue solid line and red dots). MOE are calculated after fitting using Equation (2). Results are summarized in Table 3. We observe that the MOE increases with the rise in the percentage of wood for both cases (with or without MAPE), with larger values when additive is used, which confers to the composite the strongest module. When added coupling agent, the MOE increases from 980 to $1137 \mathrm{MPa}$ for formulation with $10 \%$ wood, and increases from 1709 to $1885 \mathrm{MPa}$ for formulation with $30 \%$ wood. Three percent MAPE adjunction also allows taking benefit from wood fiber reinforcement with higher MOR for iaWPCf than for iWPCf with a better stress transfer to wood element (Table 3). Furthermore, 
Table 3. MOE and MOR for the four WPC formulations

\begin{tabular}{lllll}
\hline & iWPCf & \multicolumn{3}{l}{ iaWPCf } \\
\hline $\begin{array}{l}\text { Percentage } \\
\text { of wood fiber }\end{array}$ & 10 & 30 & 10 & 30 \\
MOE (MPa) & $980(14)$ & $1709(100)$ & $1137(26)$ & $1885(27)$ \\
MOR (MPa) & $15.6(0.4)$ & $13.6(0.7)$ & $16.4(0.6)$ & $21(0.3)$ \\
\hline
\end{tabular}

Values are the mean over all the tensile tests. SD values are given within parentheses.

the MOR of the iWPCf (without additive) decreases with the rise in the percentage of wood fibers. On the other hand, it increases to $16.4 \mathrm{MPa}$ for iaWPCf10 and up to $21 \mathrm{MPa}$ for iaWPCf30. In fact, this increase also can be due to a certain modification of the parameters during the injection process, but it does not contradict the general tendency and these results are in agreement with the literature. ${ }^{14}$ Finally, results of strain measurements by $3 \mathrm{D}-\mathrm{DIC}$ are very close to those obtained by mechanical extensometer. ${ }^{14,15}$

\section{Spatial strain localization during tensile test}

It is known that WPC are heterogeneous materials that exhibit some strain heterogeneities, for example, during tensile. ${ }^{17}$ To analyze these phenomena, spatial variations of the longitudinal strain fields measured by 3DDIC during tensile test are observed. Only WPC with $30 \%$ wood fibers are analyzed, with or without MAPE additive. Figure 5 shows eight color maps of the longitudinal strain field $\varepsilon_{y y}$ of iWPCf30 sample for various times up to breaking. Figure 6 is similar but concerns the WPC with additive (iaWPCf30 sample). In both cases, the stress-strain values corresponding to these maps are indicated by dots (triangles) in Figure 4. Color maps presented in Figures 5 and 6 confirm that the strain field is very heterogeneous and randomly distributed even for quite small deformation level. The crack appears at the surface at random in both cases (iWPCf30 and iaWPCf30) but the material with additive becomes heterogeneous slightly more rapidly (up to $t \quad 60 \mathrm{~s})$ than the one without additive $(t \quad 80 \mathrm{~s})$ : at $t \quad 100 \mathrm{~s}$, the strain amplitude (maximum value minus minimum value) is equal to $0.89 \%$ for the iWPCf30 sample and to $1.31 \%$ for the iaWPC30 sample. However, at $t \quad 200 \mathrm{~s}$ the strain amplitude is equal to $9.15 \%$ for the iWPCf30 sample and to $4.16 \%$ for the iaWPC30 sample, showing that the apparent strain heterogeneity is not so linked to the difference in modulus between the fibers and the matrix, but is mainly a consequence of local microscopic fractures between the fibers and the matrix. The failure of the iWPCf30 specimen obviously occurs before the one with additive. The coupling agent (MAPE) increases the mechanical performance by postponing the failure between the fibers and the HDPE. Of course for small strain levels, the small strain heterogeneity is due to the stiffness difference between wood fibers and HDPE matrix. It is also reported, by carefully observing the 3 D-DIC strain field evolution, that high-strain domains (HSD) are more pronounced in the boundary of the specimens whatever the considered material. These observations have been also reported in the work of Godara et al. ${ }^{17}$ The authors suggest that it is due to the propagation of preexisting microcracks or microvoids which is easier at the free edges than in the middle of the sample. Such microcracks are probably caused by the fact that the samples are produced by injection process. However, some additional studies have been done on homogeneous materials like aluminum metallic specimens during tensile test, and if the ROI is defined correctly, no preponderant strain level have been observed near the free edges, showing that our observations are not artifacts from the DIC method. It is interesting to note that, for instance, for the iWPCf30 sample (Figure 5), the macroscopic crack is not propagated precisely from one of the localized HSD area which can be observed at $t 80 \mathrm{~s}$, $t \quad 100 \mathrm{~s}$, and $t \quad 130 \mathrm{~s}$ (at $t \quad 60 \mathrm{~s}, t \quad 100 \mathrm{~s}$, and $t \quad 150 \mathrm{~s}$ for the iWPCf30 sample; Figure 6), but appears at $t \quad 150 \mathrm{~s}$ just before the peak of stress (respectively at $t 200 \mathrm{~s}$ for the iaWPCf30 sample). For that kind of material, the internal structure is damaging under tension with the increase of microscopic fractures between fibers and matrix corresponding to the strain heterogeneity increase. Consequently, the damage of iWPCf30 and iaWPCf30 seems to develop during all these tests, but the maximum stress is reached as soon as the main macroscopic crack is propagating.

Theses phenomena are obviously linked to the spatial distribution of wood fibers in the HDPE matrix during the manufacturing of the specimens by the injection process, which is circular in our study. Indeed, iWPCf30 microstructure has been observed by X-ray tomography using the image analysis derived from mathematical morphology. The images obtained give information on the random fiber orientation in the HDPE matrix. Reconstruction methods of fiber network have been investigated and the general principle of the tomography technique has been described in previous papers. ${ }^{32,33}$ To enhance the visualization of the composite components, wood fiber has been traced with potassium iodide. The local absorption coefficient in the composite components is finally transformed in 2D image of gray levels: dark gray corresponds to wood fibers and light gray represents HDPE matrix. The analyzed volume is a longitudinal cross-section of $9.3 \times 9.3 \mathrm{~mm}^{2}$ in the plane of the specimen by $1.16 \mathrm{~mm}$ in the thickness. With a pixel resolution equal to $7.75 \mu \mathrm{m}$, the size of the observed surface is $1200 \times 1200$ pixels $^{2}$ (about $86 \mathrm{~mm}^{2}$ ). This pixel size 

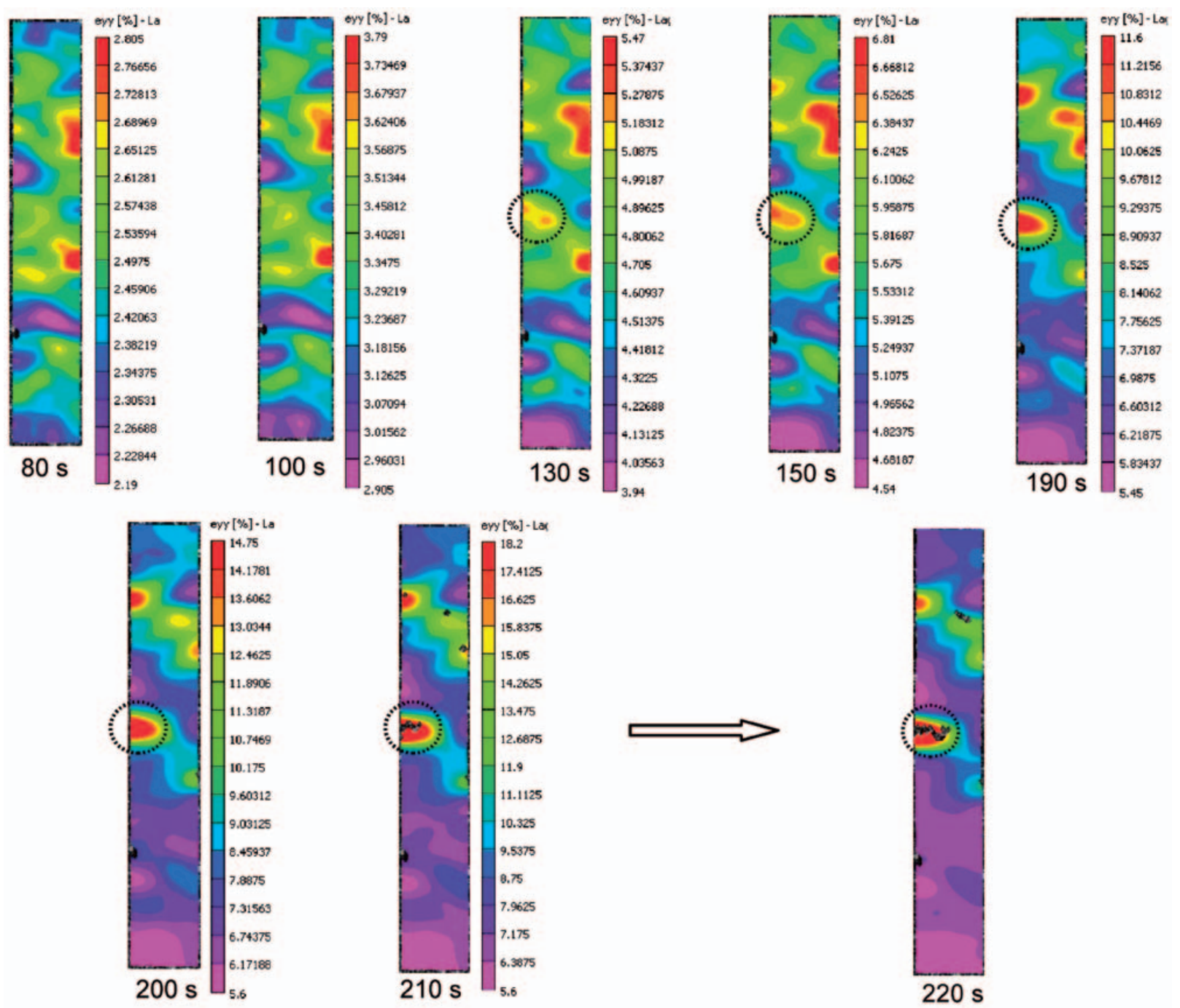

Figure 5. Longitudinal strain field measured by 3D-DIC during the tensile test of an iWPCf 30 specimen ( $30 \%$ wood without additive). Note: Breaking occurs at 220 s.

insured a high resolution throughout the entire reconstructed surface. Figure 7 shows the iWPCf30 microstructure and gives a very good description of fiber orientation in the HDPE polymer: it suggests a circular preferential direction due to the injection process. Process plays an important role on the reinforcement distribution in the matrix. Therefore, the orientation of the wood fibers in WPC affects the mechanical properties.

It is important to note, however, that using 3D-DIC the strain spatial distribution can be observed only on the surface of the samples, under the generally admitted assumption that the behavior observed on the surface of the sample is representative of the behavior in the volume. It is guessed that there is a heterogeneity through the thickness strain distribution, but not probably exactly the same as observed on the surface of the sample, because of the spatial distribution of the wood fibers in the matrix. This cannot be characterized using (surface) 3D-DIC but using volumetric 3D imaging tools such as X-rays computed microtomography (and in situ facilities) combined with the extension to volumetric images of DIC techniques. ${ }^{34}$

\section{Strain heterogeneity for various wood contents}

In the following section, we will study the degree of heterogeneity using the 3D-DIC technique on specimens with $10 \%$ and $30 \%$ wood fibers. A method for investigating the degree of the strain heterogeneity consists in analyzing the spatial distribution function of the longitudinal strain over the ROI for each mean strain 

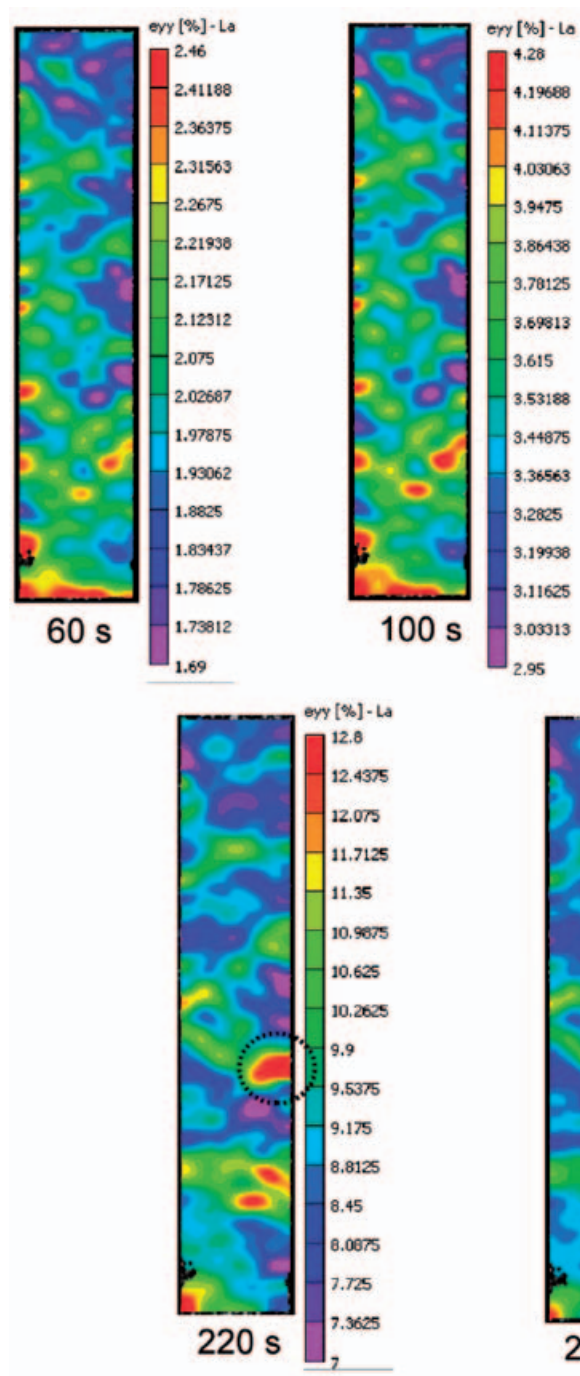
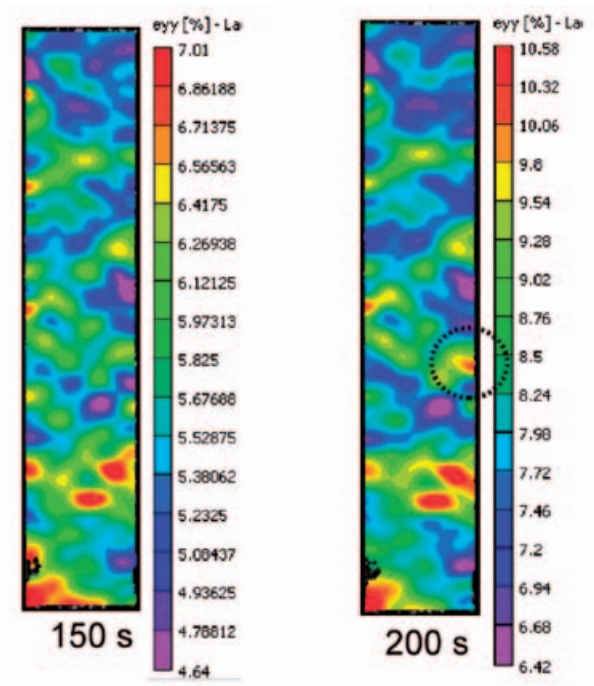
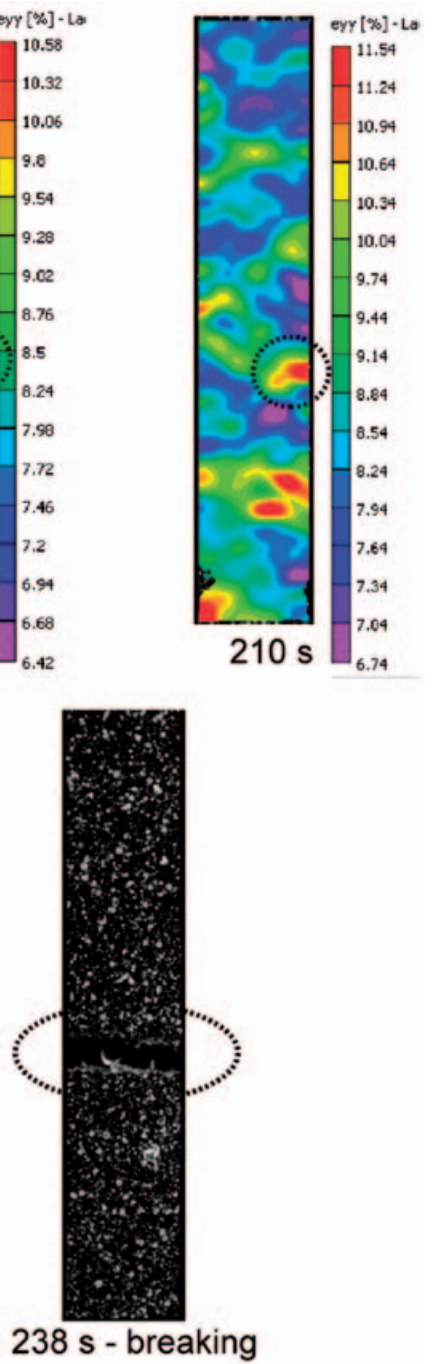

Figure 6. Longitudinal strain field measured by 3D-DIC during the tensile test of an iaWPCf 30 specimen $(30 \%$ wood + additive). Note: Breaking occurs at $238 \mathrm{~s}$.

level and each specimen. As that gave too much data, only the strain SD and its mean value have been analyzed. The strain SD is obviously related to the strain gage (optical gage size) chosen in the 3D-DIC parameters (Three-dimensional DIC section). Consequently, a sensitivity study has been done for several strain gage values and several mean strain levels. Results based on strain fields corresponding to the iWPC30 tensile test (Figure 11) are presented in Figure 8. Results for other formulations showed similar tendencies. As expected, the strain SD decreases when increasing the optical gage size (spatial averaging). It can be concluded also that the DIC method is limited by its spatial resolution (the optical gage size) which is in our case larger that the mean size of the wood fiber and close to the size of the larger wood fiber (only $10 \%$ of the wooden fibers have a length of more than $1.5 \mathrm{~mm}$ ). Because strain gradients are present, we have chosen the minimum value allowed by the software for the strain spatial resolution (about $1.2 \mathrm{~mm}$ ), insuring that the measured strain value is smaller but not so far from the true strain value.

First, it is necessary to analyze the strain field of a pure HDPE specimen to verify the homogeneity. Figure 9 shows a color map of the strain field at $t 200 \mathrm{~s}$, and the mean strain and the strain spatial SD vs. time for pure HDPE during tensile. Strain is obviously homogeneous since the strain amplitude at $t \quad 200 \mathrm{~s}$ is very small $\left(6.9 \%<\varepsilon_{y y}<7.22 \%\right.$; Figure 9(a)), and in this case, the SD presented in Figure 9(b) may be associated with the uncertainty of the strain measurement by the 3D-DIC method, from $1.5 \times 10^{-4}$ to $6 \times 10^{-4}$ in a strain range from $0 \%$ to $7 \%$ (less than $1 \%$ of the average strain value). Without any changes 
in the method and in the image correlation parameters, the same tests are conducted with an iWPCf10 sample (Figure 10) and an iWPCf30 sample (Figure 11). By observing Figures 10 and 11, it is clear that the degree of heterogeneity increases with the rise in percentage of injected wood. For $10 \%$ wood fiber, the value of the spatial SD of the longitudinal strain is relatively significant (approximately $4 \%$ of the average strain value), whereas for $30 \%$ wood fiber the value of the SD becomes very significant (until over $15 \%$ of the average strain

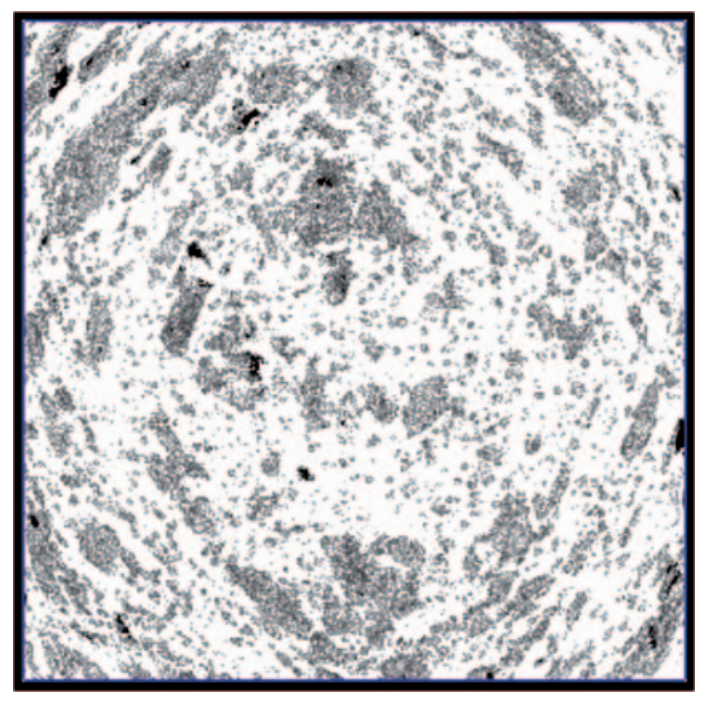

Figure 7. Rendering of iWPCf30 (30\% wood fiber content) after tomography reconstruction. value). It is found also that the strain heterogeneity increases with the increase of average longitudinal strain, almost proportionally for $10 \%$ wood fiber but in a exponential way for the sample which contains $30 \%$ of wood. One may suppose that two different phenomena take place as there is $10 \%$ or $30 \%$ of wood content and after the (linear) elastic limit is reached: for small amount of wood the strain localizations are due to microscopic internal failures (micro-void in the matrix, microscopic cracks as well as very local

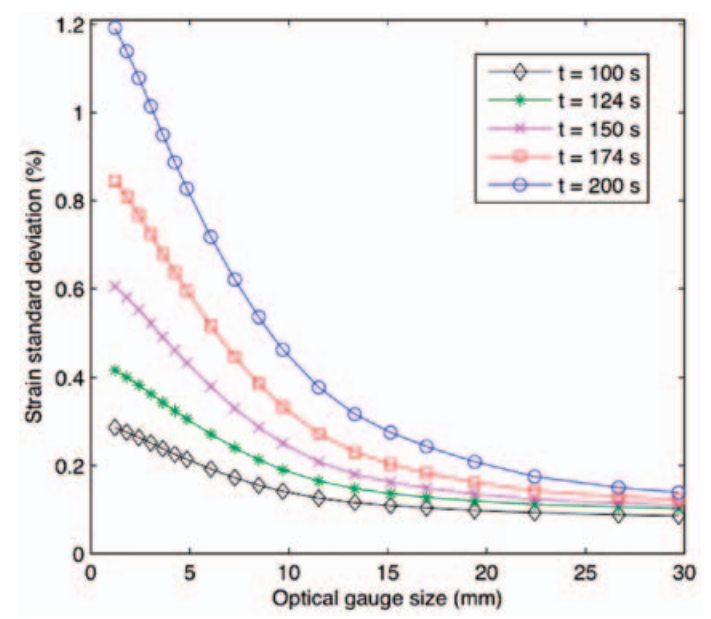

Figure 8. Evolution of the strain SD function of the optical gage size (parameter of the 3D-DIC software). Note: Times in the legend of the figure correspond to times on the abscise in the Figure II.
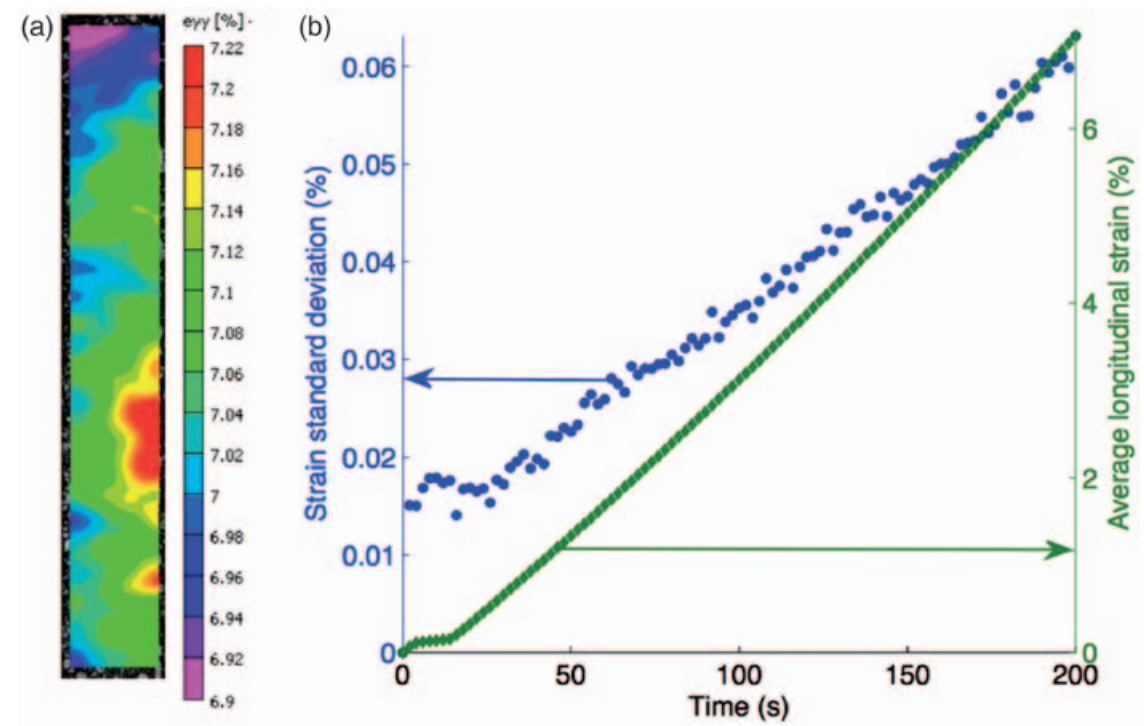

Figure 9. Analysis of the strain heterogeneity of a pure HDPE tensile sample: (a) longitudinal strain field at $t$ the 3D-DIC longitudinal strain spatial SD and mean strain vs. time. 

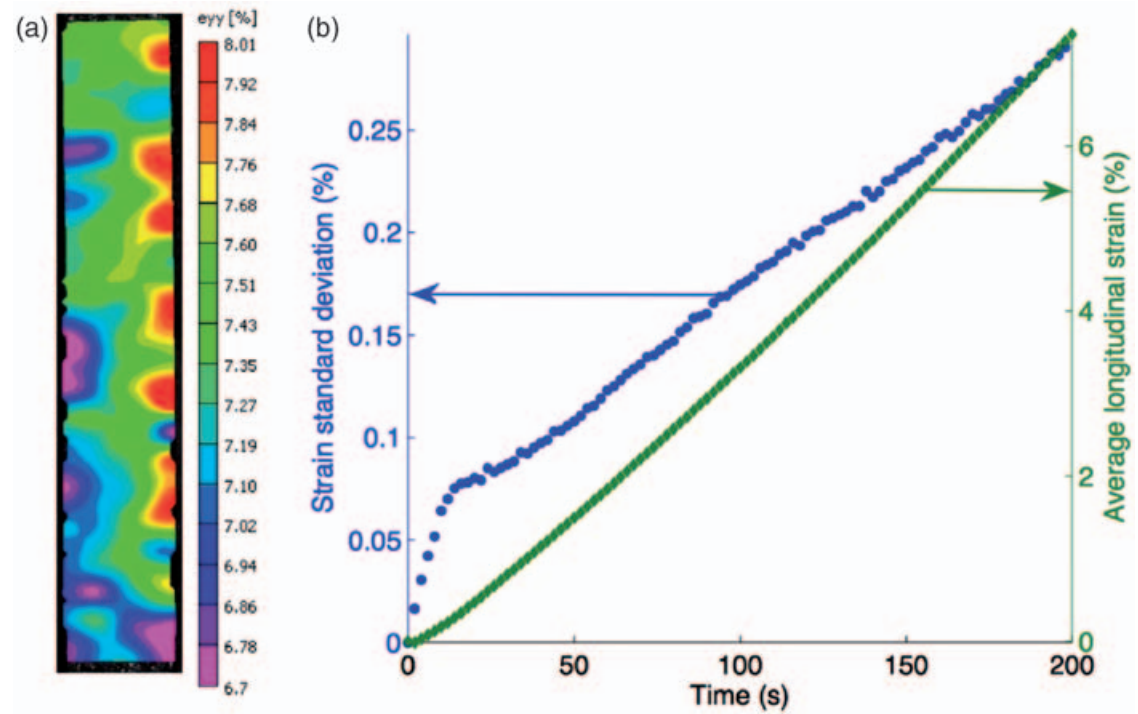

Figure 10. Analysis of the strain heterogeneity of an iWPCfI0 tensile sample: (a) longitudinal strain field at $t \quad 200 \mathrm{~s}$ and (b) evolution of the 3D-DIC longitudinal strain spatial SD and mean strain vs. time.
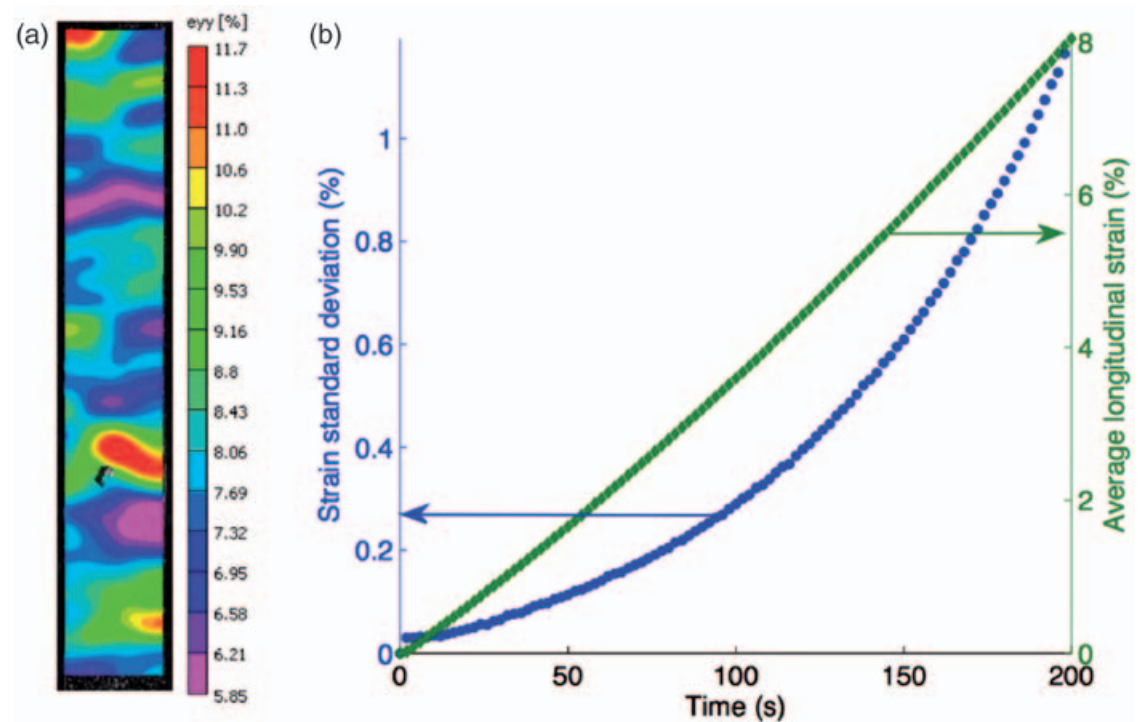

Figure II. Analysis of the strain heterogeneity for an iWPCf30 tensile sample: (a) longitudinal strain field at $t \quad 200 \mathrm{~s}$ and (b) evolution of the 3D-DIC longitudinal strain spatial SD and mean strain vs. time.

interfacial debonding between wood and HDPE) that increase proportionally with the strain level. The damage of the internal structure comes from all these microscopic phenomena. There is probably a continuous creation of microcracks and decohesion between wood and matrix, and probably not coalescence of the microcracks. Indeed no breaking occurs during the tensile tests for the specimens containing $10 \%$ of wood fibers (Figure 4) until very large strains are reached. For $30 \%$ wood in the HDPE matrix, the strain localizations increase in an exponential way with the strain level because, after the linear elastic regime and above strains corresponding to small strain localizations that are due to microscopic internal failures, the amount of strain creates coalescence of the microcracks and (at least) one macroscopic fracture is created. It seems confirmed by plotting histograms of strain fields of Figures 9(a), 10(a), and 11(a) (Figure 12). The histogram for $10 \%$ of wood is almost symmetric and rather close to the one corresponding to a Gaussian 

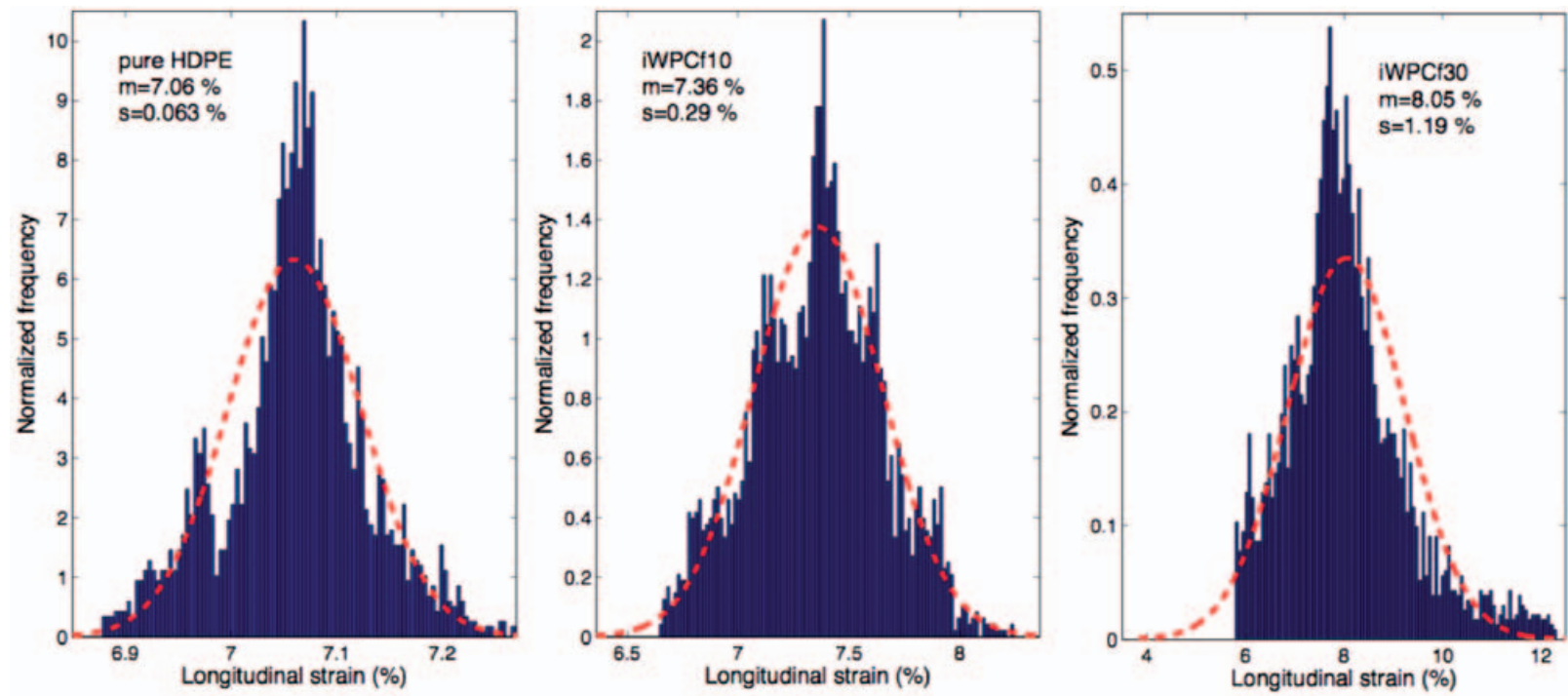

Figure 12. Histograms of the strain fields of Figures 9(a), I0(a), and II(a). Note: The curves in dashed line are the normal distribution computed with the corresponding measured mean $(m)$ and SD $(s)$.

distribution, although this distribution widens with regard to the one corresponding to the strain field of the pure HDPE. On the other hand, the histogram for $30 \%$ of wood tightens but is not symmetric any more: there is a zone with strain up to $12 \%$ on the right corresponding to the development of the macroscopic fracture.

To summarize, for WPC without MAPE additive, the degree of heterogeneity increases both with wood contents and strain levels. As one shows that the heterogeneity is linked to the local damage (microscopic crack and decohesion between fibers and polymeric matrix), the damage and thus the loss of mechanical properties (for sufficiently high strain levels, i.e., after the elastic regime) increases also with the wood contents and strain levels. Coalescence of microscopic internal failures which creates macroscopic fractures is only observed for the $30 \%$ of wood content.

\section{Conclusion}

The 3D-DIC measurement method has been used on specimens of wood fiber/HDPE composites with and without additive during tensile tests. This method has enabled us to better analyze the mechanical behavior during the damage of these kinds of WPC. On the one hand, it is confirmed that average measurements by $3 \mathrm{D}$ DIC give results very close to measurements by mechanical extensometers. Obviously, the vision-based measurements are contactless and not dependent on the position of the sensor. On the other hand, full-field measurements provided by 3D-DIC make it possible to observe strain spatial distributions. We showed that the apparent strain heterogeneities observed during the tensile tests of materials with or without MAPE additive are not so linked to the difference in modulus between the constituents, but are mainly a consequence of local microscopic fractures between fibers and matrix. The MAPE coupling agent increases the mechanical performance by postponing the failure between the fibers and the HDPE. The study of the impact of wood contents for WPC without MAPE additive showed that the degree of heterogeneity increases both with wood contents and strain levels, as the damage and thus the loss of mechanical properties (after the elastic regime). Experiments of morphological aspects of fracture using SEM observations are in progress to validate our assumptions and will be the subject of a forthcoming paper.

\section{Acknowledgments}

The authors wish to acknowledge Correlated Solutions Inc. for providing the Vic $3 \mathrm{D}^{\circledR}$ software. The authors wish also to aknowledge Prof. Habib Sammouda (LETTM, H Sousse, Tunisia), Prof. Alain Graciaa (IPRA, UPPA, France), Bertrand Charrier (Sylvadour, UPPA, France), and Alain Bourmaud (Univ. Bretagne Sud, France) for their scientifical support.

\section{References}

1. Rossi LM and Morton J. WPCs: putting innovation on a faster track. In Proceedings 8th International Conference on Woodfiber Plastic Composites, Madison, WI, 2325 May, 2005. 
2. Georgopoulos ST, Tarantili PA, Avgerinos E, Andreopoulos AG and Koukios EG. Thermoplastic poly mers reinforced with fibrous agricultural residues. Polym Degrad Stab 2005; 90: 303312.

3. Avelle M, Casale L, Dell'Erba R, Focher B, Maeruscelli E and Marzetti A. Broom fibers as reinforcing materials for polypropylene based composites. J Appl Polym Sci 1998; 68: 10771089.

4. Clemons C. Wood plastic composites in the United States: the interfacing of two industries. Forest Prod J 2002; 52(6): 1017.

5. Wu J, Yu D, Chan CM, Kim J and Mai JW. Effect of fiber pretreatment condition on the interfacial strength and mechanical properties of wood fiber/PP composites. J Appl Polym Sci 2000; 76: 10001010.

6. Stark NM and Matuana LM. Polymer degradation and stability: characterization of weathered wood plastic com posite surfaces using FTIR spectroscopy, contact angle, and XPS. Polym Degrad and Stab 2007; 92(10): 18831890

7. Cui $Y$, Lee S, Noruziaan B, Cheung $M$ and Tao J. Fabrication and interfacial modification of wood/recycled plastic composite materials. Compos Part A 2008; 39(4): 655661 .

8. Stark $\mathrm{N}$ and Berger M Effect of species and particle size on properties of wood flour filled polypropylene compos ite. In: Proceedings of Conference on Functional Fillers for Thermoplastics and Thermosets, Madison, USA, 1997

9. Verbeek CJR. The influence of interfacial adhesion, par ticle size and size distribution on the predicted mechanical properties of particulate thermoplastic composites. Mater Lett 2003; 57: 19191924.

10. Herrera Franco PJ and Valadez Gonzalez A. A study of the mechanical properties of short natural fiber reinforced composites. Compos part B 2005; 36: 597608.

11. Adhikary KB, Pang S and Staiger MP. Dimensional sta bility and mechanical behaviour of wood plastic compos ites based on recycled and virgin high density polyethylene (HDPE). Compos Part B 2008; 39(5): 807815.

12. Wechsler A and Hiziroglu S. Some of the properties of wood plastic composites. Build Environ 2007; 42(7): 26372644.

13. Najafi SK, Hamidinia E and Tajvidi M. Mechanical prop erties of composites from sawdust and recycled plastics. J Appl Polym Sci 2006; 100(5): 36413645.

14. Hugot $F$ and Cazaurang $G$. Mechanical properties of an extruded wood plastic composite: analytical modeling. J Wood Chem Technol 2008; 28: 283295.

15. Michaud F and Hugot F. Mechanical behaviour of wood plastic composite product for decking application. In: Proceedings of International Conference on Recent Advances in Composite Materials (ICRACM), New Delhi, India, 2023 February, 2007.

16. Srentovic A, Muller U and Gindl W. Mechanism of stress transfer in a single wood fiber LDPE composite by means of electronic laser speckle interferometry. Composites Part A 2006; 37(9): 14061412.

17. Godara A, Raabe D, Bergmann I, Putz R and Müller U. Influence of additives on the global mechanical behavior and the microscopic strain localization in wood reinforced polypropylene composites during tensile deformation investigated using digital image correlation. Compos Sci Technol 2009; 69: 139146.

18. Sutton MA, Orteu JJ and Schreier H. Image correlation for deformation and shape measurements: basic concepts, theory and applications. New York: Springer, 2009.

19. Wattrisse B, Chrysochoos A, Muracciole JM and Némoz Gaillard M. Analysis of strain localization during tensile tests by digital image correlation. Expl Mech 2000; 41(1): 2939.

20. Lagattu F, Bridier F, Villechaise P and Brillaud J. In plane strain measurements on a microscopic scale by coupling digital image correlation and an in situ SEM technique. Mater Char 2006; 56(1): 1018.

21. Héripré E, Dexet M, Crépin J, Gélébart L, Roos A, Bornert $\mathrm{M}$ and Caldemaison D. Coupling between exper imental measurements and polycrystal finite element cal culations for micromechanical study of metallic materials. Int J Plast 2007; 23(9): 15121539.

22. Roters F, Eisenlohr P, Hantcherli L, Tjahjanto DD, Bieler TR and Raabe D. Overview of constitutive laws, kinemat ics, homogenization and multiscale methods in crystal plasticity finite element modeling: theory, experiments, applications. Acta Materialia 2010; 58(4): 11521211.

23. Efstathiou C, Sehitoglu H and Lambros J. Multiscale strain measurements of plastically deforming polycrystal line titanium: Role of deformation heterogeneities. Int $J$ Plast 2010; 26(1): 93106.

24. Godara A and Raabe D. Influence of fiber orientation on global mechanical behavior and mesoscale strain localiza tion in a short glass fiber reinforced epoxy polymer com posite during tensile deformation investigated using digital image correlation. Compos Sci Technol 2007; 67(11 12): 24172427.

25. Wang Y and Cuitino AM. Full field measurements of het erogeneous deformation patterns on polymeric foams using digital image correlation. Int J Solids Struct 2002; 39(13): 37773796.

26. Bergonnier S, Hild F, Rieunier JB and Roux S. Strain heterogeneities and local anisotropy in crimped glass wool. J Mater Sci 2005; 40(22): 59495954.

27. Bornert M, Vales F, Gharbi H and Nguyen Minh D. Multiscale full field strain measurements for micromecha nical investigations of the hydromechanical behaviour of clayey rocks. Strain 2010; 46(1): 3346.

28. Helm JD, McNeill SR and Sutton MA. Improved three dimensional image correlation for surface displacement measurement. Optical Eng 1996; 35(7): 19111920.

29. Vic 3D and Vic snap softwares, Correlated Solutions Incorporated, http://www.correlatedsolutions.com/2010.

30. Robert L, Nazaret F, Cutard T and Orteu JJ. Use of 3 D digital image correlation to characterize the mechanical behavior of a fiber reinforced refractory castable. Exp Mech 2007; 47: 761773.

31. Sutton MA, Yan JH, Tiwari V, Schreier HW and Orteu JJ. The effect of out of plane motion on 2D and 3D digital image correlation measurements. Optic Laser Eng 2008; 46(10): 746757. 
32. Buffière JY, Maire E, Cloetens $\mathrm{P}$, Lormand $\mathrm{G}$ and Fougères R. Characterization of internal damage in a MMCp using $\mathrm{X}$ ray synchrotron phase contrast microto mography. Acta Materialia 1999; 47(5): 16131615.

33. Maire E, Buffière JY, Salvo L, Blandin JJ, Ludwig W and Létang JM. On the application of $\mathrm{X}$ ray microto mography in the field of material science. $A d v$ Eng Mater 2001; 3(8): 539546.

34. Lenoir N, Bornert M, Desrues J, Bésuelle P and Viggiani G. Volumetric digital image correlation applied to $\mathrm{X}$ ray microtomography images from triaxial compression tests on argillaceous rock. Strain 2007; 43: 193205. 